\title{
Driving Organizational Innovation as a form of Intrapreneurship within the Context of Small Businesses
}

\author{
Sonia Aguilar \\ Fort Hays State University \\ Edward F. Vengrouskie \\ The Jack Welch Management Institute \\ Robert A. Lloyd \\ Fort Hays State University
}

In past decades the majority of intrapreneurship research refers to the process of improving organizational profitability, thus enhancing the competitive position within large organizations, while largely ignoring such value to smaller companies (Antonic \& Hirsch, 2003; Garvin \& Levesque, 2006; Ibrahim, 2016; Kocjancic \& Bojnec, 2013). The purpose of this article is to stress the importance of practicing entrepreneurship, known as intrapreneurship, within the context small businesses. It is our belief that small businesses, like their larger counterparts, must evolve within a highly competitive environment where innovation is vital. We argue that intrapreneurship is not exclusively for large firms.

\section{INTRODUCTION}

The terms intrapreneurship and corporate entrepreneurship are described in the literature as being more apt for large corporations and are best applied to dynamic environments. Some researchers have used a narrower definition focusing primarily in large corporations, while smaller companies were excluded from the study (Hathway, 2009; Pinchot, 2010). Studies reveal that innovation research in organizations has been mostly in the area of technological innovation (Cader \& Badulescu, 2015; Meyer. 2013). There has been a shift in recent years into a non-technological type of innovation. The argument that organizational innovations are not produced by research and development but are the result of entrepreneurial employee behavior leads to the understanding of organizational innovations as a form of intrapreneurship within the context of small businesses. As a result, the innovation that takes place within the context of the small business environment becomes as salient and relevant as the transformative processes taking place in their larger, corporate counterpart. Research on intrapreneurship and innovation within small business is sparse, and as such the importance of this sector needs to be better understood and contextualized. Despite the unique challenges that small business owners face (Lloyd \& Vengrouskie, 2019), research has not fully investigated these dynamics. 
Our primary goal in presenting this article is to review the literature and present intrapreneurship within the context of small businesses. Our focus will include differences between entrepreneurship and intrapreneurship, idea generation, factors driving innovation, creating a culture of innovation, designing new products and reconfiguration recombination of resources, internal coalition building, persuading management, resource acquisition, planning and organizing, and how these can impact success of small businesses.

\section{Intrapreneur Defined}

There are important differences between entrepreneurship and intrapreneurship. Intrapreneurship distinctly belongs to the domain of employee behavior and faces specific limitations that a business hierarchy and an internal business environment may impose on individual initiative as well as specific possibilities for support that an existing business may offer to a nascent entrepreneur (de Jong \& Wennekers, 2008 p. 24). So, while the intrapreneur depends on private resources of capital and on market for equity and debt, the intrapreneur can and must leverage resources provided by the organization. Whereas entrepreneurs commercialize their novel solutions to external markets and diverse customers, intrapreneurs must sell their novel ideas to decision-makers within the organization (Dutton, Ashford, O'neill Hays, \& Wierba, 1997). Ultimately intrapreneurs overcome the internal constraints of a centrally managed economy instead of trying to survive in a free market. Intrapreneurship and corporate entrepreneurship is defined as an internal process where an individual within the existing system is looking for business opportunities, without taking into account the established formal channels.

\section{Idea Generation}

Researchers have significantly narrowed their focus on product (process) innovation and the body of knowledge on determinants and mechanisms has grown extensively. Whereas other types of innovation are hardly to be found in current research (Ganter \& Hecker, 2014).

Investigating whether organizational innovations are not fabricated by way of institutionalized research and development nor by dedicated $R \& D$ may help bridge the gap between innovation and entrepreneurial studies. Instead, organizational innovations frequently derive from entrepreneurially inclined individuals or intrapreneurs within the company. These intrapreneurs do not follow the customary way of doing business but rather engage with experimentation of new processes or techniques. As they acquire the support of management and corporate, their initiatives take the form of an internal venture aimed at the implementation and internal commercialization of their inventions throughout the organization. Therefore, they fall into the realm of internal venturing and intrapreneurship.

Often, intrapreneurs are usually at the middle-management or operational level and making the development of new processes, products, or techniques is less significant and visible. These individuals exploit opportunities by combining knowledge and/or resources in new ways. They promote their inventions by acquiring the support of co-workers and management and getting the necessary support for resource allocation to make the implementation possible. Idea generation is considered to be the production of new and useful ideas applicable to the perceived opportunity. Access to new information and interpretation and combination of established pieces of information are the raw materials from which new means-ends frameworks are fabricated. The availability of such material is determined by the intrapreneur's own prior knowledge and experience as well as access to further knowledge resources within the organization (Ozgen \& Baron, 2007). The mere availability of knowledge and information is not a sufficient condition for the generation of new and useful ideas, but it requires the re-organization and re-interpretation of acquired information and knowledge in innovative ways. It requires the employee to be creative thus, forming a block for intrapreneurship. Opportunities are usually poorly structured, thus, exploiting the recognized opportunity by selecting and reorganizing pieces of information together with conceptual knowledge often results in forming a new framework (Hennessey \& Amabile, 2010). 


\section{Organizational conditions}

Organizational conditions drive and catalyze the emergence of organizational innovations. If organizational innovations are the products of intrapreneurial activity, then the determinants of entrepreneurship are the main antecedents to organizational innovation. Organizational conditions that trigger intrapreneurial employee behavior are in place by management who often stimulate, foster or contribute to organizational innovation. As organizational innovation has been shown to be an important source of a firm's competitive advantage, wealth, and growth (Hecker \& Ganter, 2014) its stimulation and steering should be of particular concern to management. Managing organizational innovations therefore means driving and directing intrapreneurial employee behavior by attending to both the individual level (e.g., HR practices that attract entrepreneurially inclined employees) and the organizational level.

Managerial measures of influence and intervention, that may facilitate and foster organizational innovation include: employee selection, training and personnel development. Other managerial measures include having a reward system in place, job definition (to allow time allocation on work activities) and resource allocation.

\section{Creating a Culture of Innovation}

Managers and leaders are required to understand the direction of the business and match it to advances in technology and create roadmaps that are flexible and agile to support the business growth. Their core responsibility is to understand when it is time to change, what to change and what to endure. Forward thinking leaders are building systems and innovating in ways that will create virtuous cycles for a generation or more (Meyer, 2013, p.58).

Culture is an organization's collective assumptions, norms, and values (Organizational Culture, 2018). It defines what is, and what is not acceptable behavior. Using both positive and negative reinforcement. Leaders hold the keys to creating a culture that values and supports innovation. They can establish innovative culture and encourage experimentation and learning by ensuring that their expectations, processes, and incentives are all closely aligned. Moreover, research clearly shows that the collective nature of culture has a distinct impact on workplace motivation (Lloyd \& Mertens, 2018). As a result, there should be clear guidelines for acceptable risks and rewards that should be communicated to employees. There should be processes in place to ensure that the organization as a whole is able to learn and benefit from innovation. Companies want to be innovative but do not do much to create the right incentives for their employees to take risks. Most big companies are about avoiding failure, and failure should not be the goal, but is should be okay to fail when it comes to innovation. A well-managed company has predictable results because they control the environment and avoid surprises because they are typically bad. Thus, management is about not having unpredictable outcomes, while innovation is considered to be an unpredictable outcome (Meyer, 2013, p.26).

According to Meyer (2013), to foster innovation, companies need to assertively take some amount of their resources that they can responsibly put at risk, some amount of their people that they can responsibly allow to do things that will probably fail. If they fail, the company is prepared to deal with it but if it succeeds, they will increase the rate at which the world gets better solutions to problems. In the past, especially in large organizations, any failure jeopardized reputations, careers, and jobs. As a result, people naturally avoided risk. When failure happened rather than learning and then sharing what they had learned with others, people often felt the need to minimize the failure, even cover it up. This mind-set is still deeply embedded in most large organizations today and reinforced in ways that are not just limited to promotion or pay but basically eliminate innovation (Meyer, 2013, p.51).

To move forward, leaders should introduce and maintain a failure tolerant culture. It requires that they dig deep into the organization to ferret out practices that encourage the old mind-set and replace them with approaches that support managed risk-taking and leverage the learning from failure in the interest of innovation. Calculated risks seek the optimal risk/reward trade-off in a way consistent with clear organizational guidelines and practices. These guidelines specify the tolerable limits of downside 
exposure (e.g., investment, resource time, reputation, etc.) and structure innovation initiatives in a way that allows them, if necessary, to fail early and with minimal investment. Failures within these limits are clearly learning experiences. To make those failures yield some value, however, leaders must also ensure that the lessons are actually learned and shared with others, so they will not be endlessly repeated.

\section{REFERENCES}

Antonic, B., \& Hisrich, R.D. (2003) Clarifying the intrapreneurship concept. Journal of Small Business \& Enterprise Development, 10(1), 7-24

Cader, O., \& Badulescu, D. (2015) Entrepreneur, Entrepreneurship and Intrapreneurship, A Literature Review. Annals of the University of Oradea, Economic Science, 2(XXIV), 658-664

De Jong, J., \& Wennekers, S. (2008). Intrapreneurship Conceptualizing entrepreneurial employee behavior. SCALES. Retrieved from https://core.ac.uk/download/pdf/7074625.pdf

Dutton, J. E., \& Ashford, S.J. R.M. Hayes, E., \& Wierba, E.E. (1997). Reading the wind: How middle managers assess the context of selling issues to top management. Strategic Management Journal, $18(5), 407-423$

Garvin, D.A., \& Levesque, L.C. (2006). Meeting the Challenge of Corporate Entrepreneurship. Harvard Business Review 84(10), 102-112,150

Ganter, A., \& Hecker, A. (2014). Configurational paths to organizational innovation: qualitative comparative analyses of antecedents and contingencies. Journal of Business Research, 67(6), $1285-1292$

Hathway, D. (2009) A Blueprint for Strategic Intrapreneurship, A Dissertation For the Degree of Master of Business Administration of the University of Warwick.

Hennessey, B. A., \& Amabile, T. M. (2010). Creativity. Annual Review of Psychology, 61, 569 - 598.

Ibrahim, D.M. (2016). Intrapreneurship. Washington \& Le Law Review, 73(4), 1741-1793.

Intuit (2009). Defining Small Business Innovation. Retrieved from https://http-

download.intuit.com/http.intuit/CMO/intuit/futureofsmallbusiness/intuit_fosb_report_march_200 9.pdf

Kocjancic, J., \& Bojnec, S. (2013). Intrapreneurship, competition and company efficiency. Managing Global Transitions, 11(2) 161-179.

Lloyd, R. A., \& Vengrouskie, E. F. (2019). Digital circumvention as a means to overcome geographic limitations: Defining the new rural entrepreneurial ecosystem. Journal of Strategic Innovation and Sustainability, 14(3).

Lloyd, R. A., \& Mertens, D. (2018). Expecting more out of Expectancy Theory: History urges inclusion of the social context. International Management Review, 14(1), 28-43.

Meyer, M. M. (2013). The Innovator's Path. Library of Congress. Organizational Culture (2018). Retrieved from https://ebrary.net/3030/management/organiational_culture

Ozgen, E., \& Baron, R.A. (2007). Social sources of information in opportunity recognition: Effects of mentors, industry networks, and professional forums. Journal of Business Venturing, 22(2), 174192

Pinchot, G. (2010). The Pinchot Perspective. In Search of a Future Worth Living. Retrieved from http://www.pinchot.com/2010/01/back-to-intrapreneuring.html 